\title{
Mortes e crimes cometidos com armas de fogo na Cidade Autônoma de Buenos Aires, 2002
}

\author{
Firearm-related deaths and crime in the autonomous \\ city of Buenos Aires, 2002
}

Hugo Spinelli 1

Marcio Alazraqui ${ }^{1}$

Gabriela Zunino ${ }^{1}$

Hernán Olaeta 2

Héctor Poggese ${ }^{3}$

Carola Concaro ${ }^{3}$

Sidonie Porterie ${ }^{3}$

${ }^{1}$ Universidad Nacional de Lanús. Calle Venezuela 356, $2^{\circ}$ piso, C1095AAH, Ciudad de Buenos Aires, Argentina.

megyps@unla.edu.ar

${ }^{2}$ Dirección Nacional de Política Criminal, Ministerio de Justicia y Derechos Humanos.

${ }^{3}$ Proyecto Planificación Participativa y Gestión Asociada, Facultad Latinoamericana de

\begin{abstract}
Violence is one of the most serious challenges in Latin American societies. Possession and use of small arms and light weapons are considered to be among the main factors behind it. The aim of this paper is to describe deaths and crimes involving the use of a firearm in the City of Buenos Aires in 2002, focusing the health, justice and police sectors. Data on mortality and crimes were obtained from the National Systems for vital statistics and criminal information; data on firearm seizures were supplied by the Argentine Federal Police. Household interviews conducted for a previous research on firearmrelated victimization were also used. An index of violent incidents was developed by police station. There were 1,304 deaths from violence, of which $23.7 \%$ were caused by a firearm. The police filed 171 proceedings on the charge of homicides with criminal intent, of which $60 \%$ had been committed with a firearm. Of the 2,108 interviewed individuals, $6.7 \%$ were victims of a crime committed with a firearm. In 9.6\% of surveyed households there was a firearm. Seized firearms added up to 1,887. The index of violent incidents was higher in police stations in the southwestern area of the city that has worse living conditions. The impact of violence and its relation to firearms features as a major issue in the public agenda.
\end{abstract}

Key words Violence, Firearms, Homicide, Crosssectorial action, Maps
Resumo A violência se constitui em um dos problemas mais graves da América Latina. O uso de pequenas e leves armas de fogo é considerado o principal responsável por esse fato. O objetivo do presente trabalho é descobrir, a partir de dados do setor de saúde, justiça e polícia, o número de mortes e crimes envolvendo armas de fogo ocorridos na cidade de Buenos Aires, em 2002. Os dados sobre mortalidade e crimes foram obtidos dos Sistemas Nacionais de Estatísticas Vitais e Informação Criminal, e os dados sobre apreensão de armas de fogo foram disponibilizados pela Polícia Federal Argentina. Utilizaram-se também dados de uma investigação anterior, realizada por meio de entrevistas domiciliares a respeito de vitimização por armas de fogo. Durante o período, ocorreram 1.304 mortes violentas, das quais 23,7\% foram provocadas por armas de fogo. Dos 171 indiciamentos policiais por homicídio doloso, $60 \%$ haviam sido cometidos com armas de fogo. Das 2.108 pessoas entrevistadas, 6,7\% haviam sido vitimas de crimes cometidos com arma de fogo. Foram apreendidas 1.887 armas de fogo. A taxa de eventos violentos registrados foi maior nas delegacias da zona sudoeste da cidade, que se caracteriza por condições de vida mais precárias. O impacto da violência e sua relação com armas de fogo constituemse em um tema relevante da agenda pública.

Palavras-chave Violência, Armas de fogo, Homicídio, Ação intersetorial, Mapeamento 


\section{Introdução}

O combate à violência parece ser um dos mais sérios desafios nas sociedades latino-americanas. No fim do século 20 , já era a principal causa de morte na América Latina em pessoas na faixa etária de 15 a 44 anos 1 .

No mesmo período, segundo a Organização Mundial da Saúde (OMS), 63\% dos homicídios foram causados por armas de fogo no mundo inteiro. Na América Latina, a taxa ultrapassou $80 \%{ }^{2}$. À semelhança da África, a taxa de homicídios em nosso subcontinente é cerca de três vezes mais alta do que a do restante das regiões ${ }^{1}$. Acredita-se que a América Latina apresente a mais elevada taxa específica de homicídios causados por armas de fogo do mundo - aproximadamente três vezes mais alta do que a taxa africana; cinco vezes mais do que a da América do Norte, Europa Central e Leste da Europa; e 48 vezes mais do que a da Europa Ocidental ${ }^{3}$.

A posse e o uso de armas de fogo estão entre os principais fatores subjacentes aos níveis crescentes de violência. Alguns autores observaram que as áreas com maior número de armas de fogo apresentam taxas de homicídios causados pelas mesmas mais elevadas, e que a posse doméstica de armas de fogo para autodefesa aumenta a probabilidade de alguém da unidade domiciliar vir a ser vítima de homicídio ${ }^{2,4-6}$.

Em termos precisos, a posse e o uso de armas leves e de pequeno porte estão relacionados à violência tanto em países com altas taxas de homicídio quanto nos que apresentam taxas historicamente baixas. As armas leves ou de pequeno porte são definidas como "as que podem ser usadas e portadas por uma ou duas pessoas, tais como revólveres, escopetas, rifles e metralhadoras leves"7. Graças a tamanho, fáceis aquisição e uso, baixo custo e durabilidade, sua utilização difundiu-se nas últimas décadas por todo o mundo, tornando-as a causa da maioria das mortes e lesões nos confrontos entre indivíduos 8 .

A Argentina não constitui exceção à regra no que tange à violência e a sua correlação com armas de fogo. O setor judiciário, por meio do Ministério da Justiça e de Direitos Humanos, informou que entre os 1.340 .529 crimes oficialmente registrados no país, durante o ano de 2002, a jurisdição com o recorde de crimes foi a Província de Buenos Aires - 26,9\% - seguida pela Cidade Autônoma de Buenos Aires (Caba) - 5,1\%\%. Portanto, foi esta última o distrito com o segundo maior número de crimes, apresentando a mais alta taxa de alegados atos criminosos -7.288 por 100 mil habitantes.
Por sua vez, a Caba, juntamente com a Província de Buenos Aires, foi responsável por $42 \%$ do total de crimes cometidos durante 2002; ambas as jurisdições, somadas às províncias de Córdoba, Santa Fé e Mendonza, concentraram quase $70 \%$ do total de crimes registrados no país9.

De todos os crimes cometidos na Caba em 2002 (202.135), 71\% foram contra a propriedade (basicamente roubos e furtos); $12 \%$, crimes contra a pessoa (lesões e homicídios dolosos e culposos); e $17 \%$, outros delitos (infrações à lei de narcóticos, crimes contra a segurança pública, etc.). Os crimes contra a propriedade registrados com maior freqüência foram roubos -75.283 casos (52\%) - e furtos -2.490 casos $(43 \%)$; os $5 \%$ restantes foram outros crimes 9 .

Por sua vez, a Polícia Federal e as forças de segurança relataram que o quociente de homicídios dolosos por local de ocorrência, em 2002, foi de 7 para 100 mil habitantes na Caba ${ }^{10}$.

De acordo com os dados do setor de saúde, o quociente de acidentes, suicídios e homicídios em 2002, na Caba, permaneceu alto em comparação a 2001, sendo o número de mortes por violência sempre mais elevado em jovens do sexo masculino, e a maioria das mortes causada por armas de fogo ${ }^{11}$. Descobertas similares foram narradas na literatura brasileira e internacional sobre causas externas ${ }^{12}$.

Esses números, retirados da avaliação de dados fornecida pelo departamento de justiça, pela polícia e pelas autoridades de saúde, mostram a importância da questão. Entendemos que a abordagem à violência deva ser multissetorial, para cobrir diferentes pontos de vista específicos de cada setor. Assim sendo, este trabalho analisa em conjunto os dados da violência e das armas de fogo provenientes de vários setores oficiais da Argentina. Usamos informações de 2002, dada a profunda crise social, política e institucional que afetou o país no interregno de 2001 a 2002.

O objetivo deste trabalho é descrever mortes e crimes com envolvimento de armas de fogo na Caba durante 2002, bem como desenvolver um índice que possibilite a identificação e o futuro monitoramento dos pontos mais turbulentos. $\mathrm{O}$ propósito é fomentar um debate que deflagre futura pesquisa multissetorial para tratar da questão da violência e das armas de fogo em termos sociais.

\section{Material e métodos}

Neste trabalho, analisamos informações de 2002 oriundas de três fontes oficiais - justiça, polícia e 
autoridades de saúde - na Cidade Autônoma de Buenos Aires, com enfoque no tema das armas de fogo.

A partir das informações fornecidas pelo setor de saúde, traçamos um perfil das mortes por armas de fogo. Com base nos dados relatados pela justiça, descrevemos as mortes específicas causadas por homicídio doloso e examinamos os dados da pesquisa de vitimização realizada para o ano em curso. Por fim, fizemos uma análise dos dados fornecidos pela polícia sobre apreensões de armas de fogo naquele ano, visando a patentear a presença de armas nos crimes com intervenção policial.

Desenvolveu-se um índice de incidentes violentos por delegacia de polícia, para contabilizar espacialmente sua freqüência na jurisdição de cada um dos distritos. Há 53 delegacias de polícia na cidade de Buenos Aires, cada uma das quais com sua própria circunscrição. Usamos as seguintes variáveis para desenvolver o índice de cada delegacia de polícia: apreensões de armas de fogo, homicídios dolosos, homicídios durante confrontos interpessoais, atos criminosos, mortes por armas de fogo, homicídios por armas de fogo e total de homicídios. Analisamos a distribuição percentual de cada uma dessas variáveis por delegacia de polícia e escolhemos a variável superior ou igual a $2 \%$. Deste modo, as delegacias de polícia foram classificadas como "superior" ou "inferior", com base nos seguintes critérios: 1) superior sempre que havia mais de cinco variáveis escolhidas para a delegacia de polícia (i.e., o valor das variáveis era superior ou igual a 2\%);2) inferior - sempre que havia cinco ou menos variáveis escolhidas (i.e., o valor era inferior a $2 \%$ ).

Adiante, facultamos a descrição da origem dos dados, da população estudada e das variáveis examinadas para cada uma das fontes utilizadas.

Setor de saúde: mortalidade por armas de fogo

Os dados sobre mortalidade por armas de fogo foram retirados de relatórios estatísticos sobre o tema, fornecidos pela Secretaria Geral de Estatísticas e Censos do Governo da Cidade Autônoma de Buenos Aires, para os residentes na cidade, e pelo Sistema de Informações Computadorizadas da Província de Buenos Aires, Subsecretaria de Planejamento de Saúde, para os não-residentes da Caba. Isto posto, no caso específico de mortes causadas por violência, o local de ocorrência tornou-se especialmente pertinente, a população estudada compreendeu pessoas que sofreram morte violenta na Caba, quer residentes ou não.

As mortes causadas por violência foram carac- terizadas com base nas seguintes variáveis: sexo, idade, delegacia de polícia interventora, tipo de morte violenta e classificação de acordo com a $10^{\text {a }}$ revisão da Classificação estatística internacional de doenças e problemas relacionados à saúde ${ }^{13}$. Estes dados foram usados em pesquisa anterior, que também descreve as etapas metodológicas de sua análise ${ }^{11}$.

Utilizamos o quociente de mortes por violência com envolvimento de armas de fogo, tomando por indicador o local da ocorrência. Estimou-se o quociente tendo como numerador o total de mortes por violência com envolvimento de armas de fogo, tanto de residentes quanto de não-residentes, dividido pela população residente da Caba. Como não há registro do número de pessoas que transitam pela cidade, que seria o denominador correto, foi impossível estimar as taxas de mortalidade por violência com envolvimento de armas de fogo; por isso, usou-se o quociente.

\section{Setor judiciário: homicídios dolosos}

As informações foram obtidas por intermédio do Sistema Nacional de Informações Criminais (SNIC), da Secretaria de Política Criminal do Ministério de Justiça e Direitos Humanos. O SNIC coleta dados de duas maneiras diferentes: com base no número absoluto de atos criminosos, registrados pela polícia e pelas forças de segurança em todo o país, consoante o Código Penal; e com base nas características de alguns crimes específicos, tais como homicídios dolosos, homicídios culposos em acidentes de tráfego nas auto-estradas e crimes contra a propriedade (roubo, furto e outras transgressões).

Para os fins deste trabalho, só foram considerados os crimes contra a pessoa que resultaram em homicídios dolosos e os crimes contra a propriedade com envolvimento de armas de fogo. Não há dados oficiais sobre lesões ou homicídios culposos causados por armas de fogo.

\section{Setor judiciário: pesquisa de vitimização}

Desde 1996, a Secretaria de Política Criminal do Ministério de Justiça e Direitos Humanos realiza pesquisas de vitimização em grandes centros urbanos da Argentina. Essas pesquisas têm como objetivo principal descrever o fenômeno criminal com base em entrevistas domiciliares, com uma amostragem representativa da população. As pessoas são indagadas sobre suas experiências de vitimização durante um período de tempo definido e, em geral, sobre suas opiniões a respeito de 
questões relacionadas à segurança. $\mathrm{O}$ propósito é trazer um novo instrumento de medição - a saber, a pesquisa - para a área de segurança pública, que implique a possibilidade de acessar dados sobre as chamadas "cifras negras" do crime (casos não registrados), dentre outras vantagens.

O questionário empregado nesses estudos segue as diretrizes estabelecidas pelo Instituto Inter-regional das Nações Unidas para Pesquisas sobre Delinqüência e Justiça ${ }^{14}$. Os dados analisados neste trabalho estão relacionados à vitimização por armas de fogo de residentes da Caba entrevistados em 2002.

\section{Setor policial: apreensão de armas de fogo}

Os dados sobre as apreensões de armas de fogo foram proporcionados pela Unidade de Armas e Agências da Polícia Federal. Este trabalho inclui todas as apreensões feitas na Caba em 2002, relacionadas a crimes cometidos nesse ano ou em anteriores. As informações foram analisadas com base nas seguintes variáveis: tipo de arma de fogo apreendida, tipo de crime com envolvimento de armas de fogo e mês de sua apreensão.

Para a análise por tipo de delito, as rubricas registradas pela Polícia Federal foram agrupadas segundo a classificação do Sistema Nacional de Informações Criminais da Secretaria de Política Criminal do Ministério de Justiça e Direitos Humanos.

\section{Resultados}

Setor de saúde: mortalidade por armas de fogo

Das 1.304 mortes por violência na Cidade Autônoma de Buenos Aires em 2002, 23,7\% (309 mortes) foram causadas por armas de fogo. Portanto, as mortes relacionadas ao uso de armas de fogo foram responsáveis pela mais alta percentagem de mortes violentas durante o ano, consideravelmente maior do que o restante. A taxa mais elevada foi registrada entre os residentes da cidade $(65,4 \%) ; 31,1 \%$, entre os residentes da Província de Buenos Aires; e apenas 1,2\% entre os residentes de outros lugares; em 2,3\% dos casos não houve dados sobre o local de residência da vítima.

Dos quatro tipos de morte (acidentes, suicídios, homicídios e mortes por violência ignorada) cometidos com armas de fogo, a maior percentagem dizia respeito a homicídios $(66,3 \%)$, seguida por suicídios $(31,7 \%)$. Os outros tipos de morte corresponderam a menos de 2\% (Quadro
1). O quadro 1 também mostra os quocientes dos tipos de mortes violentas com envolvimento de armas de fogo na Caba, em relação ao número de habitantes. Para os fins de interpretação desses resultados, enfatizamos, conforme indicado sob o título "Material e métodos", que trabalhamos com base em um quociente. De qualquer modo, no tocante aos suicídios, ocorridos principalmente na casa da vítima, pode-se pressupor que o quociente seja uma estimativa precisa da taxa; no entanto, para os demais tipos de morte violenta, os valores calculados superestimariam a probabilidade de morte, como no caso dos acidentes ${ }^{11}$.

A percentagem de mortes por armas de fogo foi mais alta em homens do que em mulheres: registraram-se 288 mortes em homens, correspondendo a 93,2\%, contra apenas 21 mortes em mulheres $(6,8 \%)$.

A análise específica por idade revelou que a percentagem mais alta de mortes por armas de fogo foi registrada na faixa etária de 15 a 29 anos. A mais alta percentagem correspondia ao intervalo de 15 a 19 anos (13,9\%), enquanto no intervalo de 20 a 24 a percentagem foi de $13,3 \%$, e no de 25 a 29 , de $11,3 \%$.

Segue-se, adiante, uma breve descrição da distribuição das mortes por homicídio e suicídio cometidas com armas de fogo. Nestes dois tipos de morte, a distribuição por sexo foi similar à do total de mortes violentas. Os homens, em ambos os casos, foram os mais afetados - neles, a percentagem de homicídios foi mais alta do que a de suicídios (96,1\% e 87,8\%, respectivamente).

Os homicídios por armas de fogo afetaram, principalmente, a faixa etária de 15 a 29 anos (47,7\%). Os suicídios, porém, foram mais significativos em adultos acima de 55 anos, tendo a faixa de 65 a 69 apresentado a percentagem mais alta (16,3\%).

\section{Setor judiciário: homicídios dolosos}

Conforme o SNIC, a polícia instaurou 171 inquéritos preliminares investigados pela comissão relativamente a homicídios dolosos alegados, correspondentes a menos de $1 \%$ dos crimes contra a pessoa - um número mínimo nas estatísticas oficiais para esse tipo de crime, dado que muitos casos não são registrados. $\mathrm{O}$ fato mais sério é o de lesões graves que subseqüentemente levam à morte da vítima, lançado sob a rubrica de lesões graves pela polícia e só retificado depois, em juízo.

Por outro lado, segundo a pesquisa realizada nas varas penais da Cidade de Buenos Aires, 214 processos deram entrada no sistema da justiça criminal, nos quais foi investigado homicídio 


\section{Quadro 1}

Distribuição percentual e quociente de mortes violentas por armas de fogo, por local de ocorrência. Cidade Autônoma de Buenos Aires, 2002.

\begin{tabular}{lccc}
\hline $\begin{array}{l}\text { Tipo de incidente } \\
\text { violento }\end{array}$ & $\begin{array}{c}\text { Número } \\
(\mathbf{n})\end{array}$ & $\begin{array}{c}\text { Distribuição percentual } \\
(\%)\end{array}$ & $\begin{array}{l}\text { Quociente de mortes violentas } \\
\text { por 100 mil habitantes }\end{array}$ \\
\hline $\begin{array}{l}\text { Homicídios } \\
\text { Suicídios }\end{array}$ & 205 & 66,3 & 6,8 \\
$\begin{array}{l}\text { Mortes por violência } \\
\text { ignorada }\end{array}$ & 98 & 31,7 & 3,3 \\
Acidentes & 4 & 1,3 & 0,1 \\
Total geral & 2 & 0,6 & 0,1 \\
\hline
\end{tabular}

Fonte: Elaborado pelos autores, com base nos Relatórios Estatísticos sobre Mortalidade (SRM), 2002.

doloso em potencial. Para os fins da investigação, examinaram-se 194 casos - isto é, 90,6\% do total -, detectando-se 209 vítimas fatais. Em conformidade com esses dados, o quociente de homicídios dolosos por local de ocorrência foi de sete vítimas por 100 mil habitantes. Destes, 60\% dos homicídios dolosos foram cometidos com armas de fogo; a faixa etária mais afetada foi a de 18 a 35 anos. Setenta e seis por cento das vítimas de homicídio (209) não estavam armadas no momento do incidente.

Os dados revelaram dois subgrupos distintos: homicídios dolosos causados por confronto interpessoal e homicídios dolosos cometidos durante roubo. Como são considerados de natureza diversa, associamos o primeiro grupo à resolução violenta de conflito, e o segundo, à dinâmica criminal. Vale a pena indicar as diferenças entre os dois tipos de homicídio. Para os homicídios dolosos causados por confronto interpessoal, a maioria das vítimas não estava armada (92\%), e os instrumentos causadores da morte eram principalmente armas de fogo $(50 \%)$ ou arma branca $(30 \%)$. Para os homicídios cometidos durante roubo, 68 casos envolveram 76 vítimas. Considerável número de vítimas estava armado (43\%), principalmente com armas de fogo (88\%), o que também provocou a morte das vítimas em $69 \%$ dos casos.

Quanto aos crimes contra a propriedade, registrou-se um número mais elevado de roubos em 2002: 75.283 casos (52\%) seguidos de furtos, com 62.490 incidentes $(43 \%)$. Os 5\% restantes abrangeram outros crimes contra a propriedade.

Por outro lado, consoante às estatísticas policiais, 34\% dos roubos, i.e., mais de 25 mil casos, foram cometidos com uso de armas de fogo. Em especial os roubos a bancos e furtos de carros foram perpetrados com armas de fogo (96\% e 66\%, respectivamente). Tendo em mente que esses dados são fornecidos pela polícia, e deixando de lado os delitos não registrados (mais de 70\%, segundo a pesquisa de vitimização), constatamos o peso da participação das armas de fogo nas questões de segurança pública.

\section{Setor judiciário: pesquisa de vitimização}

De todas as pessoas entrevistadas na Caba (2.108), 40\% afirmaram terem sido vítimas de pelo menos um dos delitos pesquisados ${ }^{14} ; 6,7 \%$ delas foram vítimas de crime cometido com arma de fogo. Os delitos pesquisados em 2002 incluíram roubo com violência, furto pessoal, crimes, lesões ou ameaças sexuais e outras infrações ${ }^{14}$.

No que tange aos delitos, $68,8 \%$ dos roubos com violência foram cometidos com armas de fogo. Em 9,6\% das unidades domiciliares da Caba havia uma arma de fogo. Em conformidade com a pesquisa, a maioria das armas mantidas nas unidades domiciliares era de pequeno porte (cerca de 68,7\%). Os motivos para possuir arma de fogo alegados por metade dos entrevistados incluíam segurança ou questões relacionadas à prevenção, ao hábito de caçar e ao fato de pertencerem a forças de segurança.

\section{Setor policial: apreensões de armas de fogo}

Durante o ano de 2002, a Polícia Federal Argentina (PFA) apreendeu um total de 1.887 armas de fogo no território da Cidade de Buenos Aires. Nos primeiros quatro meses do ano, a distribuição de apreensões mostrou uma tendência estável de 174 armas de fogo detidas. Do número total de 


\section{Gráfico 1}

Distribuição, por percentuais, dos tipos de armas de fogo apreendidas pela Polícia Federal Argentina. Cidade Autônoma de Buenos Aires, 2002.

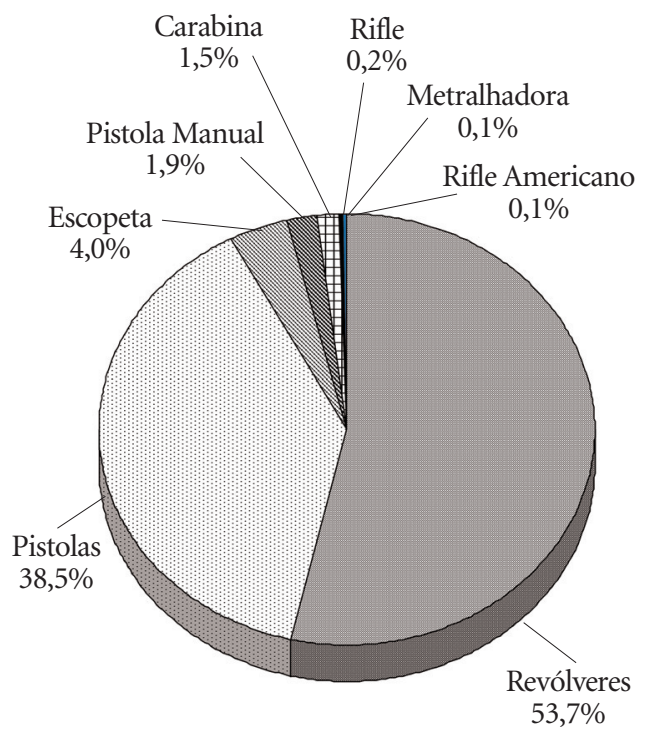

Fonte: Elaborado pelos autores, com base nos Relatórios Estatísticos sobre Mortalidade (SRM), 2002.

armas de fogo apreendidas pela PFA, 53,7\% (1.012) eram revólveres e 38,5\% (726), pistolas (Gráfico 1), totalizando $92,2 \%$ das detenções.

As 1.887 armas de fogo apreendidas pela Polícia Federal Argentina eram de 157 fabricantes diferentes: 51\% haviam sido fabricadas na Argentina, 31\%, no exterior e 19\% não puderam ser identificadas.

Do total de armas apreendidas, 43,9\% estavam relacionadas a roubo, $14,3 \%$, a crimes contra a segurança pública, e, o que é mais importante, $3,4 \%$, a homicídios dolosos. A percentagem restante se relacionava a delitos como crimes contra a administração pública, infrações à lei de drogas e outros regidos por legislação especial, entre outros.

Os critérios de classificação das apreensões cobrem as capturas registradas pela Polícia Federal e incluem tipos de crime, tipos de processo e casos de captura segundo os dados fornecidos pela Unidade de Armas e Agências da Polícia Federal Argentina. Para sistematizar os delitos, seguimos a classificação sugerida pelo Sistema Nacional de Informações Criminais (SNIC), desenvolvido pela Secretaria de Política Criminal do Ministério de Justiça e Direitos Humanos.
Análise espacial: índice de incidentes violentos por delegacia de polícia

A análise da distribuição percentual das mortes violentas cometidas com armas de fogo por delegacia revela que os resultados dos três setores judiciário, policial e de saúde - são similares no tocante à $36^{\text {a }}$ delegacia de polícia. Este distrito policial apresenta números elevados tanto de apreensões, quanto de homicídios em sua circunscrição (Quadro 2). Contudo, a 39a delegacia de polícia apresentou a maior taxa de apreensão $(6,2 \%)$, não obstante os mais baixos níveis de mortes por homicídio em sua circunscrição (0,7\%).

O número de apreensões em 2002 corresponde a uma pequena percentagem do total de atos criminosos registrados no ano (1.887 apreensões versus 193.496 atos criminosos, correspondendo a apenas 1\%).

Desenvolveu-se um índice de incidentes violentos para analisar, em termos espaciais, a sua freqüência por respectiva delegacia. Os resultados constam do quadro 2 e revelam que oito das 53 delegacias de polícia na Caba receberam classificação "superior", dado o seu índice - em cor cinza, no quadro 2 - ser $2 \%$ ou maior, em mais de cinco variáveis consideradas. As demais delegacias de polícia receberam classificação "inferior". As variáveis usadas para desenvolver o índice foram os fatores intrínsecos ao processo de violência ou não-violência em si mesmo, como as apreensões de armas de fogo.

Como se pode ver no mapa 1 , as delegacias classificadas como "superior" localizam-se principalmente na área sudoeste da Cidade Autônoma de Buenos Aires. Esta área apresenta as piores condições de vida, conforme evidenciado pela alta concentração de unidades domiciliares com necessidades básicas não satisfeitas.

\section{Discussão e conclusões}

A discussão e as conclusões estão centradas nos vários assuntos relacionados às questões estudadas neste trabalho, como tráfico de armas de fogo e de drogas, desigualdade e exclusão social, representação simbólica das armas de fogo na sociedade, espaço social como eixo da política pública, impacto econômico da violência e sistemas de informação sobre a violência.

A pesquisa revelou que a maioria dos crimes foi cometida com armas de fogo, indicando sua significativa utilização em crimes comuns em termos criminológicos. É preciso mencionar que as 
Quadro 2

Indice de incidentes violentos e distribuição percentual de mortes violentas, crimes e apreensões de armas de fogo por delegacia de polícia. Cidade Autônoma de Buenos Aires, 2002.

\begin{tabular}{|c|c|c|c|c|c|c|c|c|c|c|c|c|c|c|c|}
\hline \multirow{4}{*}{$\begin{array}{l}\text { Delegacia } \\
\text { de Polícia }\end{array}$} & \multicolumn{6}{|c|}{ Setor judiciário } & \multicolumn{6}{|c|}{ Setor de saúde } & \multirow{3}{*}{\multicolumn{2}{|c|}{$\begin{array}{l}\text { Setor policial } \\
\text { Apreensões de } \\
\text { armas de fogo }\end{array}$}} & \multirow{4}{*}{$\begin{array}{r}\text { Índice de } \\
\text { Incidentes } \\
\text { Violentos }\end{array}$} \\
\hline & \multirow{2}{*}{\multicolumn{2}{|c|}{$\begin{array}{l}\text { Atos } \\
\text { criminosos }\end{array}$}} & \multicolumn{4}{|c|}{ Homicídios dolosos } & \multicolumn{4}{|c|}{$\begin{array}{l}\text { Mortes violentas por } \\
\text { armas de fogo (homicídio, } \\
\text { suicídio e acidente) }\end{array}$} & \multicolumn{2}{|c|}{ Homicídios } & & & \\
\hline & & & Confli & to pessoal & & tal & & & $\begin{array}{r}\text { Por } \\
\text { de }\end{array}$ & $\begin{array}{l}\text { arma } \\
\text { fogo }\end{array}$ & To & & & & \\
\hline & $\mathrm{n}$ & $\%$ & $\mathrm{n}$ & $\%$ & $\mathrm{n}$ & $\%$ & $\mathrm{n}$ & $\%$ & $\mathrm{n}$ & $\%$ & $\mathrm{n}$ & $\%$ & $\mathrm{n}$ & $\%$ & \\
\hline $1^{\mathrm{a}}$ & 7.725 & 4,0 & 0 & 0 & 0 & 0 & 0 & 0 & 0 & 0 & 0 & 0 & 10 & 0,9 & Inferior \\
\hline $2^{\mathrm{a}}$ & 3.094 & 1,6 & 0 & 0 & 0 & 0 & 1 & 0,6 & 0 & 0 & 0 & 0 & 11 & 0,9 & Inferior \\
\hline $3^{a}$ & 4.556 & 2,4 & 1 & 0,5 & 1 & 1,2 & 1 & 0,6 & 0 & 0 & 1 & 0,7 & 22 & 1,9 & Inferior \\
\hline $4^{\mathrm{a}}$ & 2.303 & 1,2 & 3 & 1,6 & 0 & 0 & 4 & 2,5 & 2 & 2,2 & 3 & 2,1 & 14 & 1,2 & Inferior \\
\hline $5^{\mathrm{a}}$ & 3.877 & 2 & 2 & 1,1 & 1 & 1,2 & 1 & 0,6 & 0 & 0 & 0 & 0 & 19 & 1,6 & Inferior \\
\hline $6^{\mathrm{a}}$ & 3.202 & 1,7 & 5 & 2,7 & 3 & 3,5 & 1 & 0,6 & 0 & 0 & 2 & 1,4 & 11 & 0,9 & Inferior \\
\hline $7^{\mathrm{a}}$ & 4.436 & 2,3 & 3 & 1,6 & 2 & 2,4 & 4 & 2,5 & 0 & 0 & 2 & 1,4 & 21 & 1,8 & Inferior \\
\hline $8^{\mathrm{a}}$ & 3.343 & 17 & 4 & 2,2 & 3 & 3,5 & 3 & 1,9 & 0 & 0 & 1 & 0,7 & 13 & 1,1 & Inferior \\
\hline $9^{a}$ & 4.742 & 2,5 & 0 & 0 & 0 & 0 & 0 & 0 & 0 & 0 & 0 & 0 & 23 & 2 & Inferior \\
\hline $10^{\mathrm{a}}$ & 3.940 & 2 & 7 & 3,8 & 1 & 1,2 & 8 & 5 & 7 & 7,8 & 8 & 5,7 & 35 & 3 & Superior \\
\hline $11^{\mathrm{a}}$ & 3.599 & 1,9 & 5 & 2,7 & 2 & 2,4 & 1 & 0,6 & 0 & 0 & 1 & 0,7 & 24 & 2,1 & Inferior \\
\hline $12^{\mathrm{a}}$ & 4.765 & 2,5 & 6 & 3,3 & 2 & 2,4 & 3 & 1,9 & 1 & 1,1 & 5 & 3,5 & 45 & 3,9 & Inferior \\
\hline $13^{a}$ & 2.557 & 1,3 & 1 & 0,5 & 0 & 0 & 3 & 1,9 & 0 & 0 & 2 & 1,4 & 20 & 1,7 & Inferior \\
\hline $14^{\mathrm{a}}$ & 1.903 & 1 & 2 & 1,1 & 0 & 0 & 1 & 0,6 & 1 & 1,1 & 1 & 0,7 & 15 & 1,3 & Inferior \\
\hline $15^{\mathrm{a}}$ & 3.137 & 1,6 & 2 & 1,1 & 0 & 0 & 1 & 0,6 & 1 & 1,1 & 2 & 1,4 & 11 & 0,9 & Inferior \\
\hline $16^{\mathrm{a}}$ & 3.523 & 1,8 & 4 & 2,2 & 3 & 3,5 & 3 & 1,9 & 2 & 2,2 & 3 & 2,1 & 14 & 1,2 & Inferior \\
\hline $17^{a}$ & 5.086 & 2,6 & 1 & 0,5 & 1 & 1,2 & 0 & 0 & 0 & 0 & 0 & 0 & 29 & 2,5 & Inferior \\
\hline $18^{\mathrm{a}}$ & 2.972 & 1,5 & 3 & 1,6 & 0 & 0 & 3 & 1,9 & 3 & 3,3 & 4 & 2,8 & 9 & 0,8 & Inferior \\
\hline $19^{a}$ & 5.790 & 3 & 2 & 1,1 & 1 & 1,2 & 4 & 2,5 & 1 & 1,1 & 2 & 1,4 & 34 & 2,9 & Inferior \\
\hline $20^{\mathrm{a}}$ & 2.104 & 1,1 & 1 & 0,5 & 1 & 1,2 & 2 & 1,2 & 1 & 1,1 & 1 & 0,7 & 9 & 0,8 & Inferior \\
\hline $21^{\mathrm{a}}$ & 4.562 & 2,4 & 2 & 1,1 & 0 & 0 & 3 & 1,9 & 1 & 1,1 & 1 & 0,7 & 11 & 0,9 & Inferior \\
\hline $22^{\mathrm{a}}$ & 9.23 & 0,5 & 1 & 0,5 & 1 & 1,2 & 1 & 0,6 & 0 & 0 & 0 & 0 & 5 & 0,4 & Inferior \\
\hline $23^{a}$ & 3.774 & 2 & 4 & 2,2 & 3 & 3,5 & 4 & 2,5 & 1 & 1,1 & 3 & 2,1 & 21 & 1,8 & Inferior \\
\hline $24^{\mathrm{a}}$ & 2.170 & 1,1 & 6 & 3,3 & 2 & 2,4 & 2 & 1,2 & 1 & 1,1 & 1 & 0,7 & 22 & 1,9 & Inferior \\
\hline $25^{\mathrm{a}}$ & 2.740 & 1,4 & 0 & 0 & 0 & 0 & 2 & 1,2 & 0 & 0 & 0 & 0 & 15 & 1,3 & Inferior \\
\hline $26^{a}$ & 2.083 & 1,1 & 0 & 0 & 0 & 0 & 0 & 0 & 0 & 0 & 0 & 0 & 19 & 1,6 & Inferior \\
\hline $27^{a}$ & 2.569 & 1,3 & 1 & 0,5 & 1 & 1,2 & 2 & 1,2 & 2 & 2,2 & 2 & 1,4 & 9 & 0,8 & Inferior \\
\hline $28^{a}$ & 2.181 & 1,1 & 4 & 2,2 & 2 & 2,4 & 1 & 0,6 & 1 & 1,1 & 2 & 1,4 & 14 & 1,2 & Inferior \\
\hline $29^{a}$ & 3.716 & 1,9 & 1 & 0,5 & 0 & 0 & 3 & 1,9 & 1 & 1,1 & 2 & 1,4 & 19 & 1,6 & Inferior \\
\hline $30^{\mathrm{a}}$ & 1.861 & 1 & 3 & 1,6 & 2 & 2,4 & 2 & 1,2 & 1 & 1,1 & 1 & 0,7 & 14 & 1,2 & Inferior \\
\hline $31^{\mathrm{a}}$ & 5.046 & 2,6 & 3 & 1,6 & 2 & 2,4 & 6 & 3,7 & 1 & 1,1 & 2 & 1,4 & 7 & 0,6 & Inferior \\
\hline $32^{\mathrm{a}}$ & 3.613 & 1,9 & 18 & 9,9 & 10 & 11,8 & 7 & 4,3 & 6 & 6,7 & 8 & 5,7 & 24 & 2,1 & Superior \\
\hline $33^{a}$ & 7.046 & 3,6 & 1 & 0,5 & 0 & 0 & 7 & 4,3 & 3 & 3,3 & 3 & 2,1 & 36 & 3,1 & Inferior \\
\hline $34^{\mathrm{a}}$ & 3.486 & 1,8 & 7 & 3,8 & 3 & 3,5 & 6 & 3,7 & 5 & 5,6 & 6 & 4,3 & 26 & 2,2 & Superior \\
\hline $35^{a}$ & 4.579 & 2,4 & 1 & 0,5 & 0 & 0 & 2 & 1,2 & 0 & 0 & 0 & 0 & 42 & 3,6 & Inferior \\
\hline $36^{\mathrm{a}}$ & 3.029 & 1,6 & 20 & 11 & 14 & 16,5 & 5 & 3,1 & 5 & 5,6 & 5 & 3,5 & 46 & 3,9 & Superior \\
\hline $37^{a}$ & 4.624 & 2,4 & 3 & 1,6 & 2 & 2,4 & 4 & 2,5 & 2 & 2,2 & 2 & 1,4 & 29 & 2,5 & Inferior \\
\hline $38^{\mathrm{a}}$ & 6.236 & 3,2 & 7 & 3,8 & 2 & 2,4 & 4 & 2,5 & 4 & 4,4 & 4 & 2,8 & 38 & 3,3 & Superior \\
\hline $39^{a}$ & 3.852 & 2 & 1 & 0,5 & 1 & 1,2 & 1 & 0,6 & 1 & 1,1 & 1 & 0,7 & 72 & 6,2 & Inferior \\
\hline $40^{\mathrm{a}}$ & 4.074 & 2,1 & 3 & 1,6 & 1 & 1,2 & 2 & 1,2 & 0 & 0 & 2 & 1,4 & 18 & 1,5 & Inferior \\
\hline $41^{\mathrm{a}}$ & 3.581 & 1,9 & 3 & 1,6 & 1 & 1,2 & 4 & 2,5 & 2 & 2,2 & 4 & 2,8 & 21 & 1,8 & Inferior \\
\hline $42^{\mathrm{a}}$ & 4.271 & 2,2 & 4 & 2,2 & 2 & 2,4 & 5 & 3,1 & 2 & 2,2 & 3 & 2,1 & 36 & 3,1 & Superior \\
\hline $43^{a}$ & 4.423 & 2,3 & 1 & 0,5 & 0 & 0 & 5 & 3,1 & 3 & 3,3 & 5 & 3,5 & 19 & 1,6 & Inferior \\
\hline
\end{tabular}


Quadro 2 (continuação)

Índice de incidentes violentos e distribuição percentual de mortes violentas, crimes e apreensões de armas de fogo por delegacia de polícia. Cidade Autônoma de Buenos Aires, 2002.

\begin{tabular}{|c|c|c|c|c|c|c|c|c|c|c|c|c|c|c|c|}
\hline \multirow{4}{*}{$\begin{array}{l}\text { Delegacia } \\
\text { de Polícia }\end{array}$} & \multicolumn{6}{|c|}{ Setor judiciário } & \multicolumn{6}{|c|}{ Setor de saúde } & \multirow{3}{*}{\multicolumn{2}{|c|}{$\begin{array}{l}\text { Setor policial } \\
\text { Apreensões de } \\
\text { armas de fogo }\end{array}$}} & \multirow{4}{*}{$\begin{array}{l}\text { Indice de } \\
\text { Incidentes } \\
\text { Violentos }\end{array}$} \\
\hline & \multirow{2}{*}{\multicolumn{2}{|c|}{$\begin{array}{l}\text { Atos } \\
\text { criminosos }\end{array}$}} & \multicolumn{4}{|c|}{ Homicídios dolosos } & \multirow{2}{*}{\multicolumn{4}{|c|}{$\begin{array}{c}\text { Mortes violentas por } \\
\text { armas de fogo (homicídio, } \\
\text { suicídio e acidente) } \\
\text { Por arma } \\
\text { de fogo }\end{array}$}} & \multicolumn{2}{|c|}{ Homicídios } & & & \\
\hline & & & Conflit & o pessoal & & tal & & & & & Tot & & & & \\
\hline & $\mathrm{n}$ & $\%$ & $\mathrm{n}$ & $\%$ & $\mathrm{n}$ & $\%$ & $\mathrm{n}$ & $\%$ & $\mathrm{n}$ & $\%$ & $\mathrm{n}$ & $\%$ & $\mathrm{n}$ & $\%$ & \\
\hline $44^{\mathrm{a}}$ & 4.752 & 2,5 & 5 & 2,7 & 2 & 2,4 & 7 & 4,3 & 7 & 7,8 & 9 & 6,4 & 38 & 3,3 & Superior \\
\hline $45^{a}$ & 4.520 & 2,3 & 6 & 3,3 & 2 & 2,4 & 1 & 0,6 & 1 & 1,1 & 7 & 5 & 28 & 2,4 & Inferior \\
\hline $46^{\mathrm{a}}$ & 1.185 & 0,6 & 3 & 1,6 & 3 & 3,5 & 5 & 3,1 & 4 & 4,4 & 5 & 3,5 & 9 & 0,8 & Inferior \\
\hline $47^{\mathrm{a}}$ & 3.319 & 1,7 & 2 & 1,1 & 0 & 0 & 3 & 1,9 & 2 & 2,2 & 3 & 2,1 & 22 & 1,9 & Inferior \\
\hline $48^{a}$ & 3.770 & 1,9 & 6 & 3,3 & 4 & 4,7 & 6 & 3,7 & 5 & 5,6 & 8 & 5,7 & 38 & 3,3 & Superior \\
\hline $49^{a}$ & 2.607 & 1,3 & 0 & 0 & 0 & 0 & 4 & 2,5 & 2 & 2,2 & 2 & 1,4 & 14 & 1,2 & Inferior \\
\hline $50^{\mathrm{a}}$ & 3.617 & 1,9 & 3 & 1,6 & 2 & 2,4 & 3 & 1,9 & 1 & 1,1 & 2 & 1,4 & 20 & 1,7 & Inferior \\
\hline $51^{\mathrm{a}}$ & 2.533 & 1,3 & 2 & 1,1 & 0 & 0 & 1 & 0,6 & 0 & 0 & 1 & 0,7 & 7 & 0,6 & Inferior \\
\hline $52^{a}$ & 2.370 & 1,2 & 3 & 1,6 & 0 & 0 & 5 & 3,1 & 4 & 4,4 & 4 & 2,8 & 27 & 2,3 & Inferior \\
\hline $53^{a}$ & 3.730 & 1,9 & 6 & 3,3 & 2 & 2,4 & 4 & 2,5 & 3 & 3,3 & 5 & 3,5 & 12 & 1 & Inferior \\
\hline Total & 19.3496 & 100 & 182 & 100 & 85 & 100 & 161 & 100 & 90 & 100 & 141 & 100 & 1167 & 100 & - \\
\hline
\end{tabular}

Fonte: Elaborado pelos autores, com base em dados fornecidos pela Secretaria de Política Criminal do Ministério de Justiça e Direitos Humanos, Secretaria Geral de Estatísticas e Censos do Governo Autônomo da Cidade de Buenos Aires, Agência de Informações Computadorizadas da Província de Buenos Aires, Subsecretaria de Planejamento de Saúde e Unidade de Armas e Agências da Polícia Federal.

armas de fogo também estão relacionadas a outros tipos de crime.

Descobriu-se que o aumento de mortes cometidas por armas de fogo se relaciona a diferentes aspectos do crime organizado, como tráfico de drogas e contrabando de armas ${ }^{15}$. Ambas as questões estão vinculadas a meios de pagamento e/ou monitoramento dos pontos de venda; isso quer dizer que o tráfico de drogas foi associado ao contrabando de armas, em termos de disputas por território entre os grupos de traficantes de drogas $2,15,16$. O ônus de mortes por violência não pode ser atribuído ao vício de drogas, mas a seu tráfico, e a literatura indica que os níveis de violência relacionada ao tráfico de drogas são superiores aos do seu uso ilícito ${ }^{15,17-19}$.

A questão do tráfico de drogas e de armas é extremamente complexa, dados os motivos para a ação dos envolvidos. Isso dificulta a obtenção de informações sobre os movimentos de armas, tráfico e uso de drogas.

No tocante à fabricação das armas, a Pesquisa de Armas de Pequeno Porte revelou que todas as nações latino-americanas têm capacidade de produzir armamentos. Entre elas, o Brasil aparece como o primeiro produtor da região; a Argentina vem em quarto lugar, seguida por Chile e México. A pesquisa enfatiza o fato de as armas, depois de usadas, entrarem no "segundo" e "terceiro" mer- cados. Daí essas armas do mercado de revenda estarem envolvidas em mais de 200 mil mortes por $\mathrm{ano}^{3}$.

Na Argentina, o Registro Nacional de Armas (Renar), órgão subordinado ao Ministério da Defesa, está encarregado do registro, supervisão e controle dos usuários de armas de fogo, bem como dos fabricantes de armas e munições. Entretanto, o controle das armas sem registro fica fora do âmbito de ação do Renar, e estima-se que elas sejam, no mercado ilegal, o triplo das existentes no mercado legal.

O agravamento da situação socioeconômica é outro fator que está relacionado ao aumento da violência. Em vez da pobreza abjeta, é a crescente desigualdade social que está mais relacionada à violência, segundo descoberta de especialistas $2,4,15$, 20. Por intermédio da taxa de criminalidade, há uma forte correlação entre o comportamento criminal e a medida da desigualdade na distribuição de renda, tais como o coeficiente de Gini; a correlação entre crime e desigualdade de renda supera a existente entre crime e desemprego ${ }^{21,22}$.

A desigualdade também foi salientada como principal elemento elucidativo na pesquisa dirigida ao estudo de distribuição espacial da violência por perfil socioeconômico ${ }^{20}$. Como qualquer das dificuldades sociais em geral, a distribuição espa- 
cial da violência não se dá ao acaso; portanto, os padrões espaciais que mapeiam essa distribuição pelos territórios constituem uma estrutura para a interpretação dos processos subjacentes, especialmente para as estratégias de redução ${ }^{20}$. Na verdade, a pesquisa possibilitou a identificação de espaços mais vulneráveis à violência: centros urbanos, cidades grandes, nódulos nas redes de tráfico de drogas e fronteiras, entre outros ${ }^{20}$.

Neste trabalho, o desenvolvimento do índice de incidentes violentos foi, mais do que um exercício acadêmico, uma tentativa de entender as jurisdições de forma dinâmica, a fim de implementar políticas públicas que favoreçam a redução da violência ${ }^{23,24}$.

Como observado no mapa 1 , as delegacias classificadas como "superior" localizavam-se nos bairros do sudoeste da Cidade Autônoma de Buenos Aires. A área sul da cidade apresenta piores condições de vida do que a área norte, e é na sul que se concentra a maior quantidade de bairros carentes. Essa área apresenta a mais alta taxa de desemprego, bem como as mais elevadas percentagens de miséria e de população abaixo da linha de pobreza, com necessidades básicas não satisfeitas e educação primária incompleta ${ }^{25}$. Obviamente, não tencionamos com tal descrição estabelecer uma conexão entre pobreza e violência, pois entendemos a violência como fenômeno mais complexo do que essa mera associação linear.

Por outro lado, para compreender a enorme complexidade do assunto, enfatizamos que as armas de fogo não representam simplesmente um instrumento para roubar ou matar. Elas têm imensa força simbólica como objeto de poder e virilidade. A pesquisa qualitativa demonstra que tal poder exerce considerável influência sobre o uso de armas de fogo $^{2,15,26}$, não somente para cometer crimes mas, também, como reação à sensação predominante de insegurança.

Em conformidade com estudos semelhantes ao descrito por Kessler ${ }^{26}$, o uso de armas pelos ofensores é, acima de tudo, crucial para moldar o relacionamento com as vítimas e como veículo de exercício do poder. Utilizar uma arma de fogo é uma opção entre um conjunto claro de preferências. Por um lado, a arma de fogo é capaz de imobilizar as vítimas ou fazer com que elas fiquem nervosas - neste caso, levando a atos imprevistos que podem forçar o ofensor a atirar. Por outro lado, permite que os ofensores cometam roubos mais lucrativos, o que, por sua vez, aumenta o risco no caso de serem apreendidas ${ }^{26}$.

Além disto, as armas desempenham papel impor-

\section{Mapa 1}

Índice de incidentes violentos por delegacia de polícia, em 2002, e percentagem de unidades domiciliares com necessidades básicas não satisfeitas pelo Centro de Gestão e Participação (CGP), em 2001. Cidade de Buenos Aires.

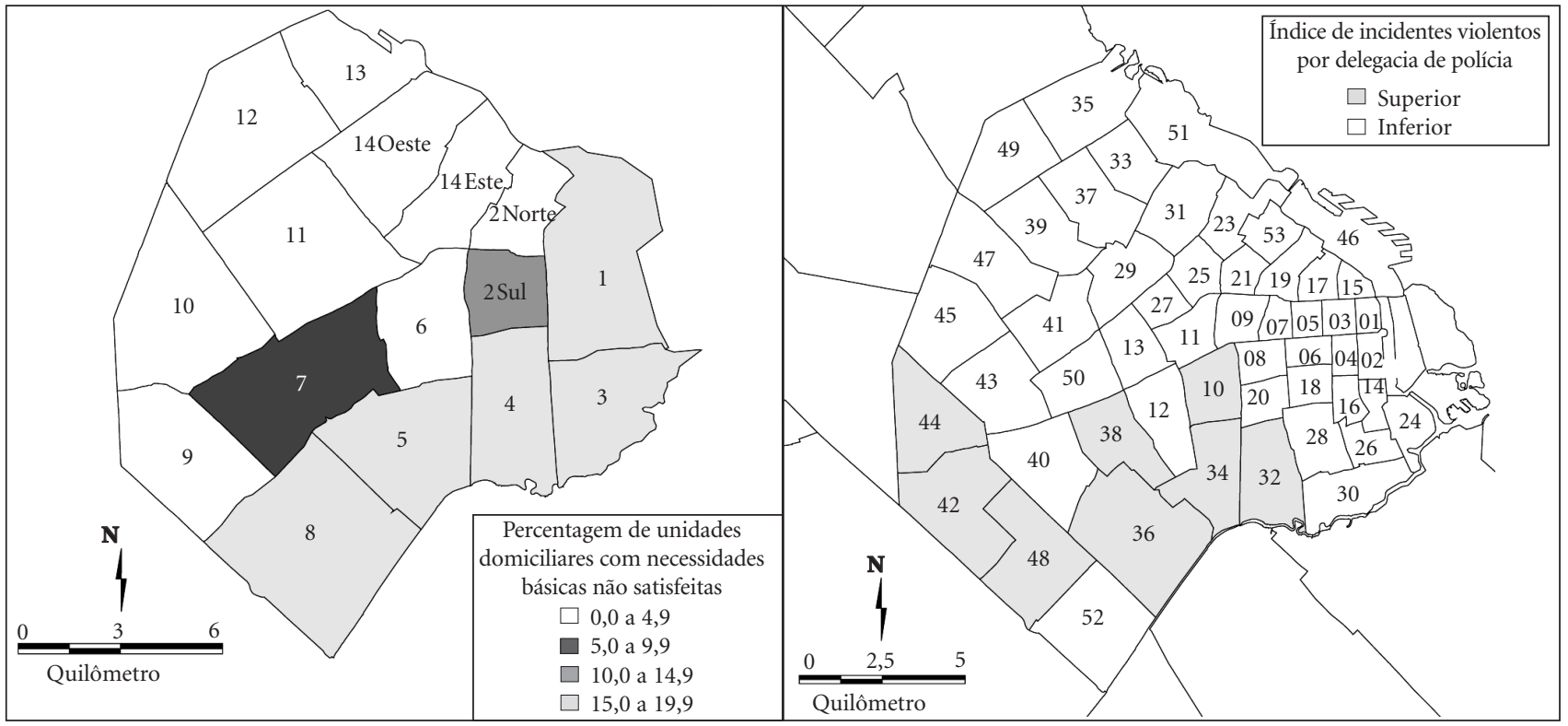

Fonte: Elaborado pelos autores, com base em dados fornecidos pela Secretaria de Política Criminal do Ministério de Justiça e Direitos Humanos, Secretaria Geral de Estatísticas e Censos do Governo Autônomo da Cidade de Buenos Aires, Agência de Informações Computadorizadas da Província de Buenos Aires, Subsecretaria de Planejamento de Saúde e Unidade de Armas e Agências da Polícia Federal. 
tante como símbolo de masculinidade, coragem e capacidade de se defender, para mostrar "virilidade"2. A subjetividade masculina parece se ancorar na virilidade e no trabalho, e os que não conseguem reconhecimento e inserção social tendem a se engajar em situações violentas - em geral, confrontos interpessoais 27 -, que resultam em todo tipo de lesões e mortes acidentais como conseqüência do uso culposo da arma.

Essas leituras ajudam a explicar o que foi descoberto de modo sistemático em vários estudos ${ }^{1,6,28-31}$, bem como neste trabalho. Os adolescentes e jovens do sexo masculino parecem ser os mais afetados por mortes violentas, em geral, e por homicídios, em particular.

Conforme afirmado por Couto et al. ${ }^{27}$, a idéia de que os processos sociais específicos por sexo geram diferenças nas taxas de morbidez e mortalidade em homens e mulheres não é novidade. Chocante e peculiar é a alta taxa de fatalidade associada a incidentes violentos com uso de arma de fogo ${ }^{2}$. Mais uma vez, as descobertas neste trabalho e em outros estudos $1,2,4-6,8,28,29$ mostram a relevância especial das armas de fogo em mortes violentas, particularmente nos homicídios.

Gostaríamos de enfatizar a relevância do ônus econômico da violência para os serviços de assistência à saúde, de cumprimento à lei e de ministração da justiça, bem como as perdas em termos de horas de trabalho, seja por meio de custos diretos ou indiretos (impacto emocional nas vítimas e seus parentes). Segundo o Relatório Mundial sobre Violência e Saúde ${ }^{1}$, a violência traz consigo altos custos para os países latino-americanos. Expressos em percentual do PIB, Colômbia e El Salvador têm as mais altas despesas da região resultantes de violência ( $5 \%$ e $4,3 \%$, respectivamente), seguidos pelo Brasil (1,9\%), Peru (1,5\%) e México (1,3\%). Não há dados confiáveis sobre os dispêndios na Argentina. Na década de 1990, estima-se que os custos diretos das mortes por violência para o setor de saúde nas Américas totalizaram dez bilhões de dólares por ano, correspondendo a cerca de $20 \%$ de todo o gasto interno com saúde pública ${ }^{32}$.

Acreditamos que haja determinados aspectos dos sistemas de informação que deveriam merecer destaque como instrumentos fundamentais de apoio à elaboração de políticas públicas. Neste sentido, Njaine et al. ${ }^{33}$ referem-se ao processo de "(des)informação" como resultado das dificuldades (treinamento profissional precário, desvalorização cultural de registros, etc.) para gerar e disseminar informações (insuficiência de dados, visão predominante na mídia, etc.). Os atuais sistemas de informação deveriam suplantar o conceito clássico tríplice de dado, informação e conhecimen- to e incorporar "comunicação" e "ação", a fim de construir cidadania social ${ }^{33-35}$.

Alguns dos autores deste trabalho realizaram pesquisas anteriores para encontrar um sistema integrado de informações entre os setores oficiais. $\mathrm{O}$ primeiro trabalho nesse tema tratou da consistência das informações sobre a mortalidade resultante da violência, fornecidas pelos setores de justiça e saúde. Encontrou-se um coeficiente de consistência global de 0,$66 ; 33,5 \%$ das informações sobre morte resultante de violência fornecidas pelo setor de saúde foram consideradas corretas, por meio de um circuito multissetorial de informações usado tanto pelo setor da saúde quanto da justiça ${ }^{36}$. O segundo trabalho explorou os fatores que afetam a qualidade das informações sobre as mortes resultantes de violência por intermédio de métodos qualitativos. Essa análise mostrou que as inconsistências no registro da violência se deviam principalmente à diversidade de concepções: enquanto o setor de saúde enfocava a vítima, os setores judicial e policial focalizavam o ofensor ${ }^{37}$.

Assim sendo, ao encarar o objetivo de integrar as informações, um dos principais problemas defrontados é o fato de o registro dos dados ser feito em termos da perspectiva da questão por parte de cada setor que compreende o Sistema Nacional de Estatística. Por exemplo, o setor de justiça analisa os dados de acordo com o tipo de homicídio - doloso ou culposo -, enquanto o setor de saúde, não. Nessa investigação, as diferenças numéricas entre os dados fornecidos pelos setores de saúde e de justiça podem se dever, em parte, à divergência na classificação de mortes violentas.

As diferenças foram encontradas basicamente no que diz respeito à perspectiva do setor específico, mas é precisamente essa perspectiva que permite encontrar as informações complementares e, por seu turno, as conclusões que indicam a seriedade e relevância do tema. Portanto, defendemos a possibilidade de se fazer uma análise integrada com as informações existentes. De qualquer sorte, salientamos que a complexidade da questão exige planejamento extremamente cauteloso do futuro trabalho multissetorial e complementação das informações existentes com estudos qualitativos que tratem das dimensões culturais e dos contextos sociais em que ocorre a violência. Somente desse modo conseguiremos uma análise do processo relacional da violência.

Dada a natureza interdisciplinar do trabalho e dos autores, foi difícil entender diferentes dinâmicas disciplinares e/ou setoriais; observamos, em geral, uma análise crítica mais profunda dentro da disciplina/setor e uma tendência ao senso comum na compreensão de outras disciplinas/setores. 
Acreditamos que se deva refletir sobre as dinâmicas do grupo, porque o problema da violência versus a segurança do cidadão é mais complexo do que disciplinas em separado.

A questão da violência não se restringe ao número de mortes e lesões provocadas; a violência e a insegurança são fenômenos complexos cujas dimensões simbólicas, subjetivas e institucionais não podem ser ignoradas. A sensação de permanente vulnerabilidade e ameaça contribui para a proliferação das soluções violentas e individualistas, em que a população tende a fazer justiça pelas próprias mãos, retirando do Estado essa sua prerrogativa. A supervisão efetiva da proliferação de armas de fogo deve levar em conta a elaboração eficiente de políticas e estratégias, o processo de implementação e monitoramento, prejudicados atualmente por preponderante licenciosidade política nesse campo.

As armas de fogo e sua relação com a violência são um assunto relevante na agenda pública de

\section{Colaboradores}

H Spinelli, M Alazraqui, G Zunino, H Olaeta, H Poggese, C Concaro e S Porterie participaram igualmente de todas as etapas da elaboração do artigo.

\section{Referências}

1. Organización Panamericana de la Salud/Organización Mundial de la Salud. Informe mundial sobre la violencia y la salud. Washington: OPS/WHO; 2003. (Publicación Científica y Técnica 588).

2. Briceño-León R, compilador. Violencia, sociedad y justicia en América Latina. 2001 [acesso em 2005 Nov]. Disponível em: http://www.clacso.org/wwwclacso/espanol/html/libros/violencia/violencia.html

3. Small Arms Survey. Small arms survey 2004: rights at risk. 2004 [acesso em 2005 Oct]. Disponível em: http://hei.unige.ch/sas/Yearbook\%202004/06\%20Crime.pdf

4. Szwarcwald CL, Castilho EA. Mortalidade por armas de fogo no Estado do Rio de Janeiro, Brasil: uma análise espacial. Rev Panam Salud Publica 1998; 4(3):161-70.

5. Cardona M, García HI, Giraldo CA, López MV, Suárez CM, Corcho DC, et al. Homicidios en Medellín, Colombia, entre 1990 y 2002: actores, móviles y circunstancias. Cad Saude Publica 2005; 21(3):840-51.

6. Peres MFT, Santos PC. Mortalidade por homídios no Brasil na década de 90: o papel das armas de fogo. Rev Saude Publica 2005; 39(1):58-66.

7. Desarme.org 2002. ¿Qué son las armas pequeñas? 2005 [acesso em 2005 Nov]. Disponível em: http://www.desarme.org/publique/cgi/cgilua.exe/sys/start.htm?sid=9\&in foid=59\&UserActiveTemplate=_desarme_es2 vários países - tais como o Brasil, onde foi realizado referendo popular para banir a comercialização de armas e munições. É claro que abolir o comércio de armas não coloca um ponto final na violência. As causas da violência são muito complexas, como supramencionado neste trabalho, e devem ser analisadas integralmente, considerando-se todas as suas inter-relações ${ }^{38}$. Banir a comercialização de armas e munições por legislação é agir contra a lógica militar e autoritária usada com freqüência na solução de controvérsias.

O impacto da violência e sua relação com as armas de fogo apresenta-se como questão primordial na agenda pública. Sua análise multissetorial, o desenvolvimento de sistemas multissetoriais de informação com expressão territorial, projeto de políticas públicas, recuperação do espaço público e debate social sobre os diferentes aspectos são algumas das tarefas necessárias, e por vezes adiadas, que deveriam ser enfrentadas para construir cidadania para todos.
8. Saín M. Informe final sobre mapeo de armas y municiones secuestradas y decomisadas. Programa de Apoyo a la Reforma Estatal y Fortalecimiento Fiscal (PAREFF). Recuperación y destrucción de armas en circulación ilícita. Proyecto Construyendo Seguridad Ciudadana del Programa de Apoyo a la Reforma Estatal y Fortalecimiento Fiscal. Buenos Aires; 2003.

9. Sistema Nacional de Información Criminal. Informe anual de estadísticas policiales. Dirección Nacional de Política Criminal. Ministerio de Justicia, Seguridad y Derechos Humanos; 2002. [acesso em 2005 Oct]. Disponível em: http://wwwpolcrim.jus.gov.ar/snic2002/InformePais/Snic2 002Parte1.pdf

10. Dirección Nacional de Política Criminal. Dirección General de Estadísticas y Censos. Centro de Estudios Legales y Sociales. Homicidios dolosos en la Ciudad de Buenos Aires, año 2002. Una investigación sobre expedientes judiciales. Ministerio de Justicia, Seguridad y Derechos Humanos, Gobierno de la Ciudad Autónoma de Buenos Aires; 2002. [acesso em 2005 Oct]. Disponível em: http://wwwpolcrim.jus.gov.ar/Dolosos/Dolosos2002 Infol.pdf

11. Spinelli H, Alazraqui M, Macías G, Zunino MG, Nadalich JC. Muertes violentas en la Ciudad Autónoma de Buenos Aires. Una mirada desde el sector salud. Buenos Aires: Organización Panamericana de la Salud; 2005. 
12. Souza ER, Ximenes LF, Alves F, Magalhães C, Bilate D, Szuchmacher AM, et al. Avanços do conhecimento sobre causas externas no Brasil e no mundo: enfoque quanti e qualitativo. In: Minayo MCS, Souza ER, organizadores. Violência sob o olhar da saúde: a infrapolítica de contemporaneidade brasileira. Rio de Janeiro: Ed. Fiocruz; 2003. p.131-60.

13. Organización Panamericana de la Salud/Organización Mundial de la Salud. Clasificación estadística internacional de enfermedades y problemas relacionados con la salud. Décima revisión. Washington: OPS/OMS; 1995.

14. Dirección Nacional de Política Criminal. Estudio de victimización: Ciudad Autónoma de Buenos Aires, 2002. Ministerio de Justicia, Seguridad y Derechos Humanos de la Nación; 2003. [acesso em 2005 Oct]. Disponível em: http://wwwpolcrim.jus.gov.ar/victimiz/victim.htm

15. Souza ER. Masculinidade e violência no Brasil: contribuções para a reflexão no campo da saúde. Rev C S Col 2005; 10(1):59-70.

16. Programa de Naciones Unidas para el Desarrollo. Armas de fuego y violencia. Programa Hacia la Construcción de una Sociedad sin Violencia; 2003. [acesso em 2005 Oct]. Disponível em: http://www.violenciaelsalvador.org.sv/index.php? module $=$ htmlpages $\&$ func $=$ display\&pid $=37$

17 Minayo MC, Deslandes SF. A complexidade das relações entre drogas, álcool e violência. Cad Saude Publica 1998; 14(1):35-42.

18. Palmer DS. Drogas y seguridad en el Mercosur. Buenos Aires: Instituto Nacional de Administración Pública; 1998.

19. Programa de Naciones Unidas para el Desarrollo. El impacto de las drogas en la violencia. Buscando soluciones. Consejo Nacional de Seguridad Pública de El Salvador, Programa Sociedad sin Violencia, Programa Hacia la Construcción de una Sociedad sin Violencia; 2004. [acesso em 2005 Oct]. Disponível em: http://www.violenciaelsalvador.org.sv/modules.php?op $=$ modload $\&$ name $=$ Downloads $\&$ file $=$ index\&re $\mathrm{q}=$ viewsdownload\&sid $=22$

20. Rojas LI, Santos SM, Barcellos C. Diferenciación espacial de la violencia en América Latina. In: Minayo MCS, Coimbra Jr. CEA, organizadores. Críticas e atuantes: ciências sociais e humanas em saúde na América Latina. Rio de Janeiro: Ed. Fiocruz; 2005.

21. Pompei E. Las consecuencias sociales de la distribución Enoikos 1999; 14:69-79.

22. United Nations Office on Drugs and Crime. The application de United Nation standards and norms in crime prevention and criminal justice. Expert Group Meeting. Vienna: Unodoc; 2003.

23. Castro MSM, Silva BFA, Assunção RM, Beato Filho CC. Regionalização como estratégia para a definição de políticas públicas de controle de homicídios. Cad Saude Publica 2004; 20(5):1269-80.

24. Macedo AC, Paim JS, Silva LMV, Costa MCN. Violência e desigualdade social: mortalidade por homicídios e condições de vida em Salvador, Brasil. Rev Saude Publica 2001; 35(6):515-22.

25. Dirección General Adjunta de APS. Análisis de situación de salud (ASIS) de la población de la ciudad de Buenos Aires, año 2003. Buenos Aires: Departamento de Epidemiología/Secretaría de Salud del Gobierno de la Ciudad de Buenos Aires; 2003.

26. Kessler G. Sociología del delito amateur. Buenos Aires: Editorial Paidós; 2004.

27. Couto MT, Schraiber LB. Homens, saúde e violência: novas questões de gênero no campo da Saúde Coletiva. In: Minayo MCS, Coimbra Jr. CEA, organizadores. Críticas e atuantes: ciências sociais e humanas em saúde na América Latina. Rio de Janeiro: Ed. Fiocruz; 2005.
28. Briceño-León R. Urban violence and public health in Latin America: a sociological framework of explanation. Cad Saude Publica 2005; 21(6):1629-64.

29. Franco S. La violencia homicida y su impacto sobre la salud en América Latina. In: Minayo MCS, Coimbra Jr. CEA, organizadores. Críticas e atuantes: ciências sociais e humanas em saúde na América Latina. Rio de Janeiro: Ed. Fiocruz; 2005.

30. Souza ER. Impacto da violência no Brasil e em alguns países das Américas. In: Minayo MCS, Coimbra Jr. CEA, organizadores. Críticas e atuantes: ciências sociais e humanas em saúde na América Latina. Rio de Janeiro: Ed. Fiocruz; 2005.

31. Sant'Anna A, Aerts D, Lopes MJ. Homicídios entre adolescentes no Sul do Brasil: situações de vulnerabilidade segundo seus familiares. Cad Saude Publica 2005; 21(1):120-9.

32. Macedo CG. Sociedad, violencia y salud: una nueva agenda para la democracia. Discurso magistral en la Conferencia Interamericana sobre Sociedad, Violencia y Salud [mimeo]; 1994 Nov 16-17; Washington, EUA; 1994.

33. Njaine K, Souza ER, Minayo MCS, Assis SG. A produç̃o da (des)informação sobre violência: análise de uma prática discriminatória. Cad Saude Publica 1997; 13(3):405-14.

34. Alazraqui M. Sistemas de información en salud: de sistemas cerrados a la ciudadanía social. Un desafío en la reducción de desigualdades en la gestión local [tese]. Salvador: Instituto de Saúde Coletiva, Universidade Federal da Bahia; 2005.

35. Njaine K, Souza ER. Informação e comunicação sobre violência: instrumentos para a cidadania. In: Minayo MCS, Souza ER, organizadores. Violência sob o olhar da saúde: a infrapolítica de contemporaneidade brasileira. Rio de Janeiro: Ed. Fiocruz; 2003. p. 269-82.

36. Alazraqui M, Spinelli H, Wilner A, Nadalich J, Olaeta H, Urquía M. Análisis de la calidad de las estadísticas sanitarias oficiales de mortalidad por causas externas: propuesta de un circuito de información intersectorial. Proyecto No 105 PPA 1. Programa de Vigilancia de la Salud y Control de Enfermedades (VIGI+A). Buenos Aires: Ministerio de Salud y Ambiente de la Nación; 2003.

37. Alazraqui M, Spinelli H, Wilner A, Olaeta H. Análisis cualitativo de la calidad de información de los sistemas estadísticos de salud y de justicia sobre muertes por violencias en la Ciudad Autónoma de Buenos Aires en 2001. Proyecto No 6 . Programa de Vigilancia de la Salud y Control de Enfermedades (VIGI+A). Buenos Aires: Ministerio de Salud y Ambiente de la Nación; 2004.

38. Minayo MCS. Diga sim! Ao referendo que pergunta sua opinião sobre a proibição de comercializar armas no Brasil. 2005. [acesso em 2005 Nov]. Disponível em: http://www.abrasco.org.br>ABRASCO

Artigo apresentado em 6/03/2006

Aprovado em 23/03/2006

Versão final apresentada em 23/03/2006 